\title{
ON INTERALLELIC CROSSING OVER
}

\author{
$\oslash$. WINGE \\ Carlsberg Laboratary, Valby, Capenhagen
}

Received 5.vii.55

IN general it can be said that genes are not arranged on the chromosome in any particular order in the sense that neighbouring genes influence the same character, but in recent years there have been reported several instances of so-called "complex genes", whose individual parts act upon the same character and which are also able to take part in crossing over.

I would like to discuss in what follows some examples of complex genes, for the results of investigations carried out during the last ten years on the inheritance of the genes responsible for fermentative ability in the yeast Saccharomyces have convinced me that a type of crossing over exists which is quite distinct from the ordinary chromatid crossing over, in that portions of genes, or, if one prefers, portions of gene molecules, are involved in the process.

\section{THE $M^{R}$-GENE IN SACCHAROMYCES}

In Saccharomyces the usual type of crossing over between the chromatids seems to prevail. This was shown by Lindegren (1949), who measured the distances between a number of genes and their respective centromeres and found them to vary from 6 to 50 units.

It is therefore remarkable that at the Carlsberg Laboratorium two instances of very close linkage between two pairs of fermentation genes have been observed; these involve linkage between one of the genes for maltose fermentation, $M_{1}$, and one of the genes for raffinose fermentation $R_{1}$, as well as linkage between another maltose-fermenting gene, $M_{3}$, and the raffinose-fermenting gene, $R_{3}$. These results have been published elsewhere (Winge and Roberts, I952, I953), and I shall only mention here that in our Hybrid $\mathrm{I} 77\left(M_{1} r_{1} / m_{1} R_{1}\right)$, in which the dominant genes were in the repulsion phase, only I crossover tetrad out of a total of 64 was found, giving a crossover value of 0.8 per cent.

The non-crossover asci from this hybrid segregated out two single spore cultures which fermented maltose but not raffinose $\left(M_{1} r_{1}\right)$ and two which fermented raffinose but not maltose $\left(m_{1} R_{1}\right)$. By employing the diploidised crossover types $M_{1} M_{1} R_{1} R_{1}$ and $m_{1} m_{1} r_{1} r_{1}$ Hybrid 189 was produced, in which the dominant genes were in the coupling phase $\left(M_{1} R_{1} / m_{1} r_{1}\right)$. Out of a total of I I tetrads derived from this hybrid, I was found to be a crossover tetrad, giving 4.5 per cent. c/o. In all, the crossover value for $M_{1}-m_{1}$ and $R_{1}-r_{1}$ was found to be I.3 per cent. With regard to the genes $M_{3}$ and $R_{3}$, which existed in the repulsion phase in our Hybrid 202, no recombination in the 
gametes was found among I I tetrads analysed. Since this hybrid was heterozygous with respect to $M_{1}, M_{3}, R_{2}$ and $R_{3}$, it was not suitable material for determining the actual degree of linkage between $M_{3}$ and $R_{3}$.

It should be apparent that although linkage in Saccharomyces has been known before, the extremely close linkage observed here between two different pairs of $M$ - and $R$-genes makes these cases distinct, and, at the same time, invalidates the view that their occurrence is a matter of chance. One is led to the conclusion that linkage, in the usual sense, is not involved here at all, but, rather, that two complex gene molecules exist: these may be designated $M_{1} R_{1}$ and $M_{3} R_{3}$. $M_{1} R_{1}$ has four allelomorphs which, according to the usual system of allelomorph designation may be called $M_{1}^{R_{1}}, M_{1}^{{ }^{r_{1}}}, m_{1}{ }^{R_{1}}$, and $m_{1}^{r_{1}}$ and which cause, respectively, the fermentation of (I) maltose and raffinose, (2) maltose, (3) raffinose, and (4) neither sugar. These allelomorphs may arise partly through mutual exchange of portions of genes, a phenomenon which is hereby termed interallelic crossing over. For example, $M_{1}{ }^{\gamma_{1}}$ and $m_{1}{ }^{R_{1}}$, through mutual exchange of parts, may become transformed into $M_{1}{ }^{R_{1}}$ and $m_{1}{ }^{{ }{ }_{1}}$.

The $M$-genes are responsible for the synthesis of maltase which hydrolyses maltose into two glucose molecules, which are then fermented through the action of the zymase complex. The $R$-genes, on the other hand, are responsible for the synthesis of $\beta$ - $h$-fructosidase, which hydrolyses both raffinose and sucrose. The fructose portion of the molecule, which is split off from the raffinose, is fermented by zymase, and the melibiose portion remains untouched. Sucrose is hydrolysed by $\beta$-h-fructosidase into fructose and glucose, both of which are fermented by zymase, which, as is well-known, is found in all species of Saccharomyces and is responsible for the fermentation of the monosaccharides glucose, fructose, and mannose.

Fig. I represents schematically a hypothetical explanation of the crossing over mechanism which is assumed to occur and which is able to explain the extremely close linkage observed between maltose and raffinose fermentative ability.

The fermentation genes are assumed to consist of complex molecules in which the chemical constitution of a loosely bound side chain determines whether maltose + raffinose, raffinose alone, maltose alone, or none of the two sugars in question can be hydrolysed through the synthesis of the specific enzymes. The gene complex may thus be designated as $M_{1} R_{1}, M_{1} r_{1}, m_{1} R_{1}$, and $m_{1} r_{1}$-or, as previously mentioned, as $M_{1}^{R_{4}}, M_{1}^{r_{1}}, m_{1}{ }^{R_{1}}$, and $m_{1}^{r_{1}}$. At the four-strand stage of meiosis it would be possible for loosely bound portions of the molecules to be exchanged without chromatid breakage, and this type of crossing over, in which the chromatid axis remains intact, I shall designate as non-axial interallelic crossing over. Such exchanges can hardly be said to be inconsistent with the principles of chemistry. Chemical processes consist in molecular exchanges with possible 
redistribution of atoms or groups of atoms. The phenomenon under discussion may be assumed to occur sporadically, or at least infrequently, since it only involves the exchange of portions of molecules of two

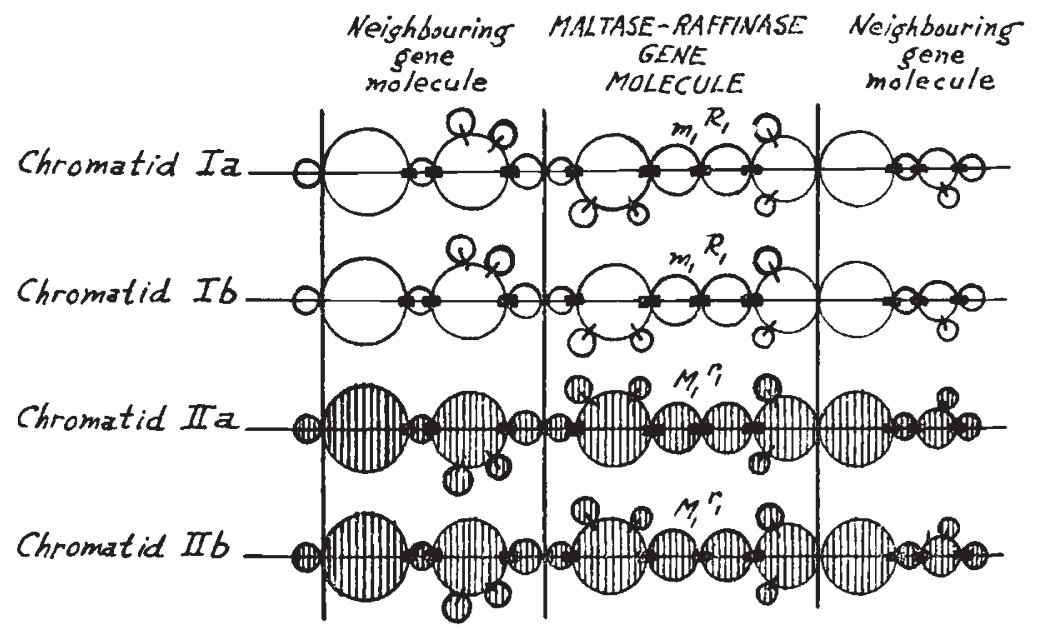

AFTER INTERALLELIC CROSSING OVER

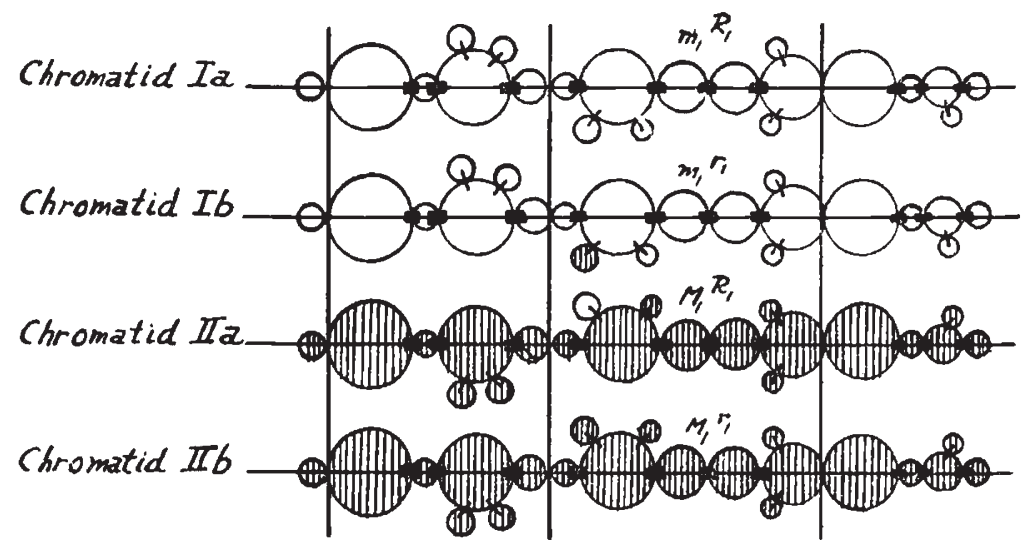

FIG. 1.-Hypothetical representation of non-axial interallelic crossing over in Saccharomyces. The chromatids are illustrated before (above) and after (below) crossing over has taken place. With regard to the complex maltase-raffinase gene, an exchange occurs between Chromatid Ib and IIa without the chromatid axis being involved. This crossing over results in two new genes, $m_{1}{ }^{{ }_{1}}$ and $M_{1} R_{1}$, which arise from the genes $m_{1} R^{1}$ and $M_{1} r_{1}$. The molecular groups (represented as circles) are bound together by thick or thin lines, indicating the strength of the bond.

genes, i.e. mutual reaction between small amounts of material. The fact that the gene molecules are in immediate contact with one another in the diplotene stage of meiosis and especially at the chiasmata would make it possible for the exchange of side chains to take place without much difficulty.

Thus, since two instances are known in Saccharomyces of close (but not complete) linkage between the ability to ferment raffinose and sucrose and 
the ability to ferment maltose, and since their presence cannot be due to a matter of chance, it must be assumed that we are here dealing with complex genes. The consequence of this assumption is not without interest, for it means that the specific enzymes synthesised by the genes in question must be chemically related-i.e. the difference between maltase and $\beta$-h-fructosidase amounts to only a portion of the whole molecule.

In the genus Saccharomyces we are fortunate in being able to study all 4 spores of a single tetrad, since they may be isolated and cultivated individually. The subsequent single spore cultures may be analysed with respect to those characters under investigation, so that it is possible to establish - with certainty whether a process resembling normal crossing over actually has taken place.

The hypothesis of non-axial interallelic crossing over set forth here may be verified or invalidated by employing suitable material. It is obvious that the presence of marker genes which are situated on the chromatid close to a gene $X$ which is suspected of taking part in interallelic crossing over would be sufficient for verification or invalidation, for if a normal crossing over occurs, the marker genes would be inherited together with $X$, whereas the occurrence of non-axial interallelic crossing over would lead to a completely different end result.

In Saccharomyces there are unfortunately no genes at our disposal which could serve as markers for $M_{1} R_{1}$ or for $M_{3} R_{3}$, and it is therefore impossible at present to determine whether or not crossing over in this organism is accompanied by chromatid breakage. It should be emphasised, however, that the occurrence of non-axial interallelic crossing over is here a theoretical possibility.

Before citing other possible instances of interallelic crossing over, it would be well to discuss its effect upon the customary measurements of the distances between the genes on a chromatid.

\section{THE EFFECT OF INTERALLELIC CROSSING OVER UPON LINKAGE MEASUREMENT}

If one imagines linkage existing between $A$ and $B$ in a hybrid $A a B b$ and assumes that the $B$ gene takes part in an interallelic crossing over in $n$ per cent. of the cases so that $b$ is actually transformed into $B$ and $B$ into $b$

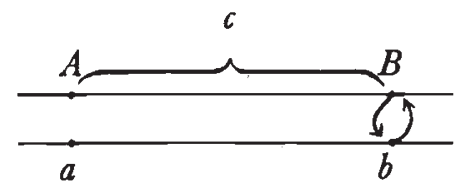

then the actual distance $c$, expressed in centimorgans by the usual linkage measurement, will appear to be

$$
c+\frac{n \text { (per cent. non } c / 0-\text { per cent. } c / 0)}{100}
$$


If the actual distance between $A$ and $B$ is, for example, 20 centimorgans, one will find with the occurrence of 5 per cent. interallelic crossing over

$$
20+\frac{5(80-20)}{100}=23 \text { centimorgans }
$$

Obviously, the more infrequent interallelic crossing over, the smaller will be its effect upon the experimental result. The greater the distance between the two genes, the less effect the process will have upon the experimental measurement. The 5 per cent. interallelic crossing over used here as an example is undoubtedly too high, so that it can be safely assumed that the measurement of the frequency of crossing over will normally not be greatly influenced by the process.

As a rule, however, interallelic crossing over will not give rise to a conversion of genes (in the sense of Winkler (I930) or of Lindegren I949) in which $B$ becomes $b$ and $b$ becomes $B$. Characteristic of interallelic crossing over will be that two new allelomorphs are formed. In the example mentioned previously in Saccharomyces, two new alleles arose, $M_{1}{ }^{R_{1}}$ and $m_{1}{ }^{{ }_{1}}$. By tetrad analysis it is possible, as already mentioned, to establish whether or not these actually do occur, but in organisms where tetrad analysis is precluded, it is doubtful whether more than one of the crossovers would be discovered. In order that the interallelic crossover gametes shall be recognised, they must both be functional ; this is improbable, and practically impossible, during crossing over at meiosis in female organs.

Thus, it can be said in general that linkage measurements will be affected only to a small degree by the occurrence of interallelic crossing over.

\section{THE $A^{b}$ GENE IN MAIZE}

Laughnan (1949, 1952) has discussed the $A$-series of allelomorphs in maize of Emerson and Anderson (1932) and stressed the remarkable relation found between mutation and crossing over, which led him to the conclusion that the $A^{b}$-gene, one of a series of allelomorphs, is of a compound nature. The wild type gene in the third chromosome is designated $A$ and is responsible for red pigmentation in the pericarp. On the other hand, $A^{b}$, which is dominant over $A$, produces a brown pericarp. The recessive allelomorph, $a$, also gives rise to a brown pericarp when it is present in a homozygous condition.

$A^{b}$ may mutate to the $A^{d}$-allele, which is responsible for a pale colour of the seeds, but $a$ has not been found to mutate to $A^{d}$. When the gene $D t$, which is located in the ninth chromosome, is present (Rhoades, 194I), the recessive a-gene may, however, at a late stage in the life cycle, mutate to allelomorphs of a higher order. Since the Inutation $A^{b} \longrightarrow A^{d}$ appears to occur simultaneously with a crossover, studies were made on segregation in a heterozygous hybrid, $A^{b} a$, which had the recessive marker genes et (etched endosperm) and 
$\lg$ (liguleless) I 3 centimorgans to the right and 33 centimorgans to the left, respectively, of the $a$-locus. The investigation was carried out by means of the following crossing :

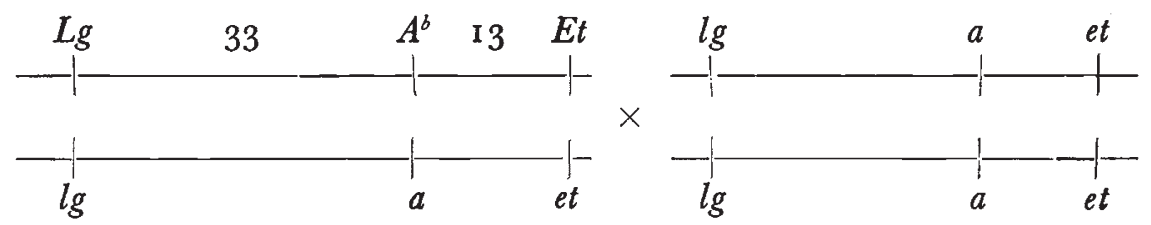

Approximately half of the seeds produced by this crossing had deep purple aleurones $\left(A^{b} A^{b} a\right)^{*}$ and half were colourless. Among many thousand purple-coloured seeds there occurred a few pale seeds, which the author suspects were $A^{d}$ mutants. After having established with certainty that they were not due to accidental inclusion of other types, the author found, finally, 7 seeds with genotypically pale pericarps which could be considered as mutants.

Now if the $A^{b}$-gene in these seeds had simply mutated to $A^{d}$, the majority of these $A^{d}$-individuals should carry the marker gene. $E t$, but, actually, 6 of the 7 had et. Laughnan states (1949, p. I 73): " Unless the change of $A^{b}$ to $A^{d}$ is in some way related to crossing over it would be expected that the frequency of crossing over in the a-et interval would be the same in sporocytes which carry $A^{d}$ as in those which transmit $A^{b}$. On this basis, of the original mutant plants approximately 13 per cent. $A^{d}$ et/a et (crossover) and 87 per cent. $A^{a} E t / a$ et (non-crossover) individuals are expected. The actual results were almost exactly the reverse of this ; six of the seven individuals were crossover types for the a-et region."

But if the "mutation" $A^{b} \longrightarrow A^{d}$ had occurred through the process of interallelic crossing over (see fig. 2) so that a group of atoms was exchanged between $A^{b}$ and $a$, transforming $a$ into $A^{d}$, it is clear that $A^{d}$ should be in the coupling phase with et and not with $E t$. Theoretically, the end result should therefore be 87 per cent. $A^{d}$ et and 13 per cent. $A^{d} E t$, which is the result observed.

Through exchanges of portions of molecules between $A^{b}$ and $a$ two new alleles will arise- $A^{d}$ and $A^{x}$, the latter having received a group of molecules from the $a$-gene and having donated, at the same time, a group of molecules to $a$. But in the case in question, it is not certain that $A^{x}$-seeds could be distinguished from $A^{b}$-seeds and as tetrad analyses are out of the question, there is actually nothing remarkable in the fact that a new allelomorph was not discovered. Laughnan himself is of the same opinion and mentions (1952, p. 388) that other possible crossover types may have escaped detection.

In Laughnan's more comprehensive study in 1948 there were obtained from a similar crossing 34 pale seeds which had arisen by mutation to $A^{d}$. Of these, 30 possessed $e t$ and $4, E t$. Also here interallelic crossing over can explain the fact that $A^{d}$ enters the coupling

" Laughnan writes " $A^{b} a a$ ", but this must be a typographical error. 
phase with et, so that by normal chromatid crossing over $4 A^{d} E t$ genotypes arise. Better agreement with the theoretically expected could not be desired.

Laughnan enlarged the scope of his investigations in $195^{2}$ by including the gene $s h_{2}$ (shrunken endosperm) in his crossings. This gene was localised at a distal position 0.25 units to the right of $a$, with which it was in the coupling phase. Unfortunately, the author's crossing experiments are described in such a way as to make them difficultly accessible. The majority of dominant genes are lacking in the genetic formulas, and it is not evident, for example, when the

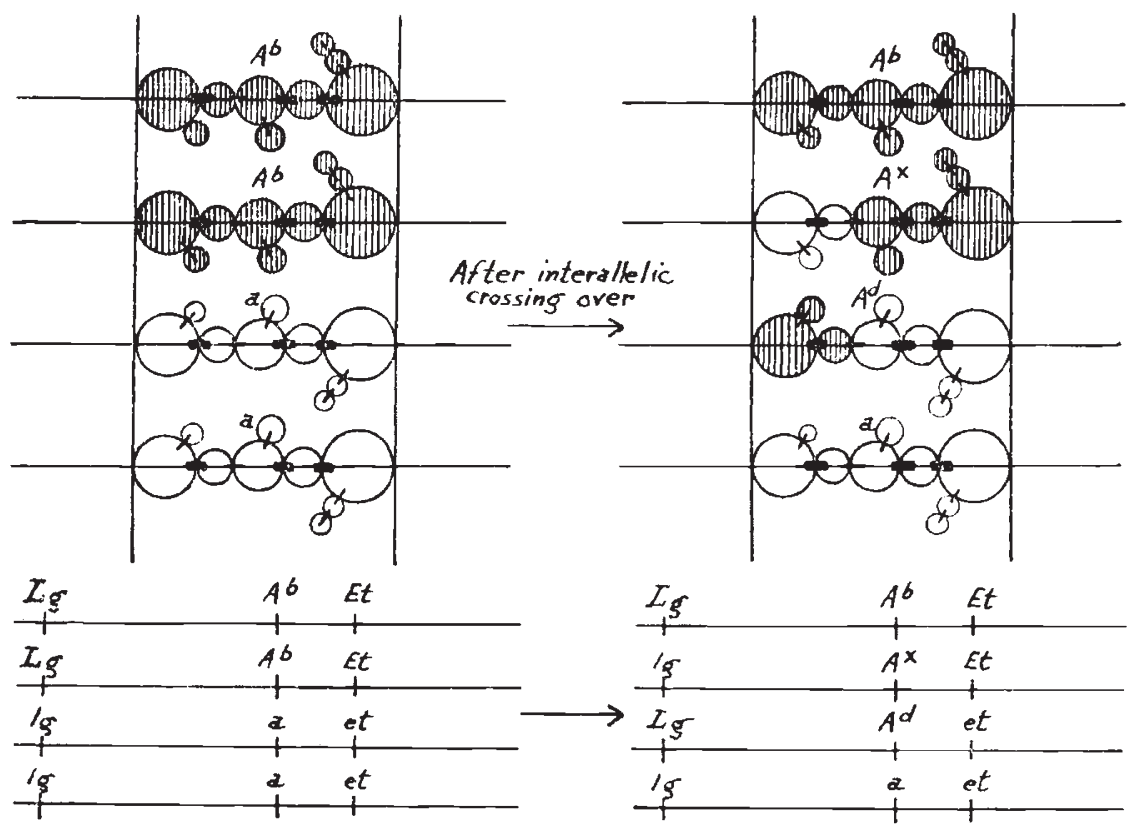

FIG. 2.-Hypothetical representation of axial interallelic crossing over in Zea. The two inner chromatids exchange axial molecular groups, the chromatid axis thus taking part in the process. Crossing over between the complex genes $A^{b}$ and $a$ results in the formation of $A^{x}$ and $A^{d}$. The linkage relations between the complex genes and the marker genes $L g$ and $E l$ are represented below.

author mentions twice (1952, page 375) " the recombinant allele of $e t$ " that he means $e t$ itself and not Et. An apparent error on the same page (" $A^{b}$ derivatives" in place of " $A^{d}$ derivatives") merely adds to the confusion.

It appears, however, from these interesting investigations that in 67 out of 7 I cases of the mutation $A^{b} \rightarrow A^{d}$, in which the $A^{d}$-mutants appeared in $A^{b} / a$ plants, crossing over occurred between $a$ and $s h_{2}$ in connection with the mutation-in spite of the fact that $A^{b}$ and $S h_{2}$ were closely linked. Again, interallelic crossing over can explain the fact that most of the $A^{d}$-progeny had the genotype $A^{d} s h_{2}$.

With respect to the combination of $A^{d}$ and the other marker gene, $l g$, Laughnan's segregation data clearly show that linkage is also 
present between $A^{d}$, which arose as a mutation from $A^{b}$, and $L g$. In this case, Laughnan's explanation is quite adequate : the $A^{b}$ gene is a compound gene, consisting of $\alpha\left(=A^{d}\right)$, which lies to the left in a proximal position and $\beta$, which lies to the right in a distal position. During crossing over, $\alpha$ and $\beta$ are separated, so that $\alpha\left(=A^{d}\right)$, together with that portion of the chromatid lying to the left, takes part in the crossing over process. It is, however, difficult to explain the occurrence of synapsis between the $a$-gene and $\alpha$ and $\beta$, respectively.

Here, a form of interallelic crossing over must be involved which is different from that assumed to exist in Saccharomyces since here the chromatids break somewhere in the middle of the gene molecule, as is seen in fig. 2. This type of interallelic crossing over may be designated as axial, since not only side chains alone are exchanged (which would result in non-axial crossing over) but also axial portions of the gene molecule itself.

The fact that tetrad analyses are precluded, and that Laughnan's assumed separation of $\alpha$ and $\beta$ can occur in I out of 1400 gametes and, under certain conditions, still more rarely, does not make it easy to construct the details in the crossing over process.

\section{THE T-GENE IN MOUSE}

Dunn's researches (I953 and earlier) on the many tailless allelomorphs of the $T$-locus in mouse may possibly be reconsidered in the light of the interallelic crossing over hypothesis, although the results are difficult to interpret, not only because of the absence of marker genes, but also because of the poor phenotypic expression of the alleles in question. Also, tail abnormalities may even occur in "normal" animals. Dunn distinguishes between "para-loci" (Laughnan's "para-alleles") and "complex-loci". Crossing over may occur with regard to the former, but not the latter. However, in this connection, Dunn emphasises that what one to-day calls "complex loci", perhaps later will turn out to be "para-loci"namely, if crossing over can be demonstrated.

There is in Dunn's material a gene, $F u$ (fused), which is strongly linked to the $T$-gene and which has an allelomorph, $F u^{K i}$ (Kink) which could theoretically be employed as a marker gene, since it appears to lie at a distance of 4 centimorgans from $T$ (Dunn and Gluecksohn-Waelsch, 1953). However, the fact that $T$ and $F u$ "combine apparent similarity in phenotypic effects with juxtaposition of the affected loci " so that even certain $t$-mutants are indistinguishable from $F u$-types leads one to speculate whether the $F u$ - $K i$ complex cannot actually be regarded as a complex gene molecule, in which interallelic crossing over takes place.

The many allelomorphs of $T$ which have been found both in nature and in the laboratory may well have arisen by interallelic crossing over. In the first place, it has been found that in the balanced lethal line $T t_{1}$ (in which $T T$ and $t_{1} t_{1}$ are lethal) many new alleles 
have arisen ; this is exactly similar to the previously mentioned case in maize, in which the $A^{d}$-gene arises from the $A^{b} a$-type. Secondly, there are several $t$-alleles which are lethal in the homozygous condition but which form viable compounds with each other. Here, defects caused by one allele may be compensated for by another allele.

\section{THE BI-GENE IN ASPERGILLUS}

The situation in Aspergillus nidulans (Roper, I950; Pontecorvo, I953) is most interesting. In this organism 3 biotinless mutant genes occur which appear to be allelomorphs. The haploids are called $b i_{1}, b i_{2}$, and $b i_{3}$, in spite of the fact that they do not always behave as true recessives. The diplophase in Aspergillus can unfortunately not be investigated directly, as it is limited to the ascus alone.

The $3 B I$-alleles are all situated 4-5 centimorgans from the gene pair $Y_{-y}$ (green-yellow), but a recombination was found in an ascus $B I_{3} b i_{1} / b i_{3} B I_{1}$ (or $B I_{2} b i_{3} / b i_{2} B I_{3}$ ), in that haploid biotin-synthesising types, $B I_{1} B I_{3}$ (or $B I_{2} B I_{3}$ ), were segregated out, although rarely; these investigations appear to show that the $B I$-alleles may be arranged in a definite order with respect to the $Y$-locus-namely, $Y-B I_{2}-$ $B I_{3}-B I_{1}$. However, the method employed for detemining the crossover values does not appear to be completely reliable. The constant use of selective substrates with the estimation of the frequency of occurrence of Aspergillus colonies obtained upon these substrates obviously can not be entirely correct. Unfortunately, tetrad analyses cannot be performed since the recombinations are so infrequent, and, in general, there appears to be no attempt to analyse tetrads (octads) in this organism.

By using a selective method Roper has produced diploid conidia and tetraploid asci, which, however, often degenerate, and the spores from tetraploid asci often show low viability. It is characteristic that a heterozygote, for example, $b i_{2} B I_{1} / B I_{2} b i_{1}$, is biotinless, in the same way as the heterokaryon, $b i_{2} B I_{1}+B I_{2} b i_{1}$ is biotinless. In order that biotin synthesis can take place, a cell nucleus containing all the biotin genes $\left(B I_{1}, B I_{2}, B I_{3}\right)$ must be present ; this situation is similar but not identical to the activity of complementary genes.

Roper states (Pontecorvo, I953, p. 2 I4) :

"Any hypothesis to explain the results obtained for the bi-locus must account for two facts : (I) The extremely close linkage of three loci, mutant alleles which determine similar or probably identical phenotypes; such close linkage for three loci is hardly likely to be a matter of chance ; and (2) the fact that the phenotype of the diploid, $b i_{2} B I_{1} / B I_{2} b i_{1}$, and the heterokaryon, $b i_{2} B I_{1}+B I_{2} b i_{1}$, are mutant and not wild type as expected from the fact that each mutant $b i$ allele tested separately is recessive."

Roper considers it most probable "that the gene as a working unit in physiological action is based on a chromosome segment larger than either the unit of mutation or recombination." This viewpoint which Muller (I 947) has also touched upon is undoubtedly the correct 
one, embracing, as it probably does, what I have called interallelic crossing over, which may be subdivided into an axial and a nonaxial type. It is obviously possible for a complex gene molecule to be composed of relatively independent molecular groups arranged in a definite order along the axis, and the investigations on Aspergillus appear to offer rather good evidence for the existence of this ordered arrangement. $B I_{2}+B I_{3}+B I_{1}$ is a complex gene molecule, and if any one of the three gene components is lacking the type is biotinless.

\section{DISCUSSION}

It has not been possible for me to find in the literature descriptions of any investigations which provide evidence for the verification of the hypothesis proposed herein. For this purpose, the existence of marker genes which are closely linked to the mutated complex gene is essential. Neither is it known to me whether tetrad analyses have been undertaken in which the relation between complex allelomorphic genes and closely situated neighbouring genes has been investigated.

On the other hand, a number of investigations on the so-called complex genes in general have already been made, and various hypotheses have been proposed as to their structure. In this connection I am reminded of Thompson's side-chain theory of gene structure (193I), in which he assumed that the gene consisted of a " protosome", to which " episomes" were bound. Thompson even supposed (p. 273) " that crossing over with its implied intimate contact at the point of breaking, is an effective agency for dislodging episomes or for transforming them to the homologous gene." These views were based upon the bar series of allelomorphs in Drosophila.

Complex genes are mentioned in several other works. Hutchinson (1934) takes Thompson's views as the basis of the explanation of the inheritance of leaf shape in Gossypium and the inheritance of several characters in other organisms. Lewis (1945) explains the StarAsteroid case in Drosophila as repeats within the same locus, and there can scarcely be any doubt that by duplications as the result of unequal crossing over, gene complexes may arise in a way which is not at all similar to interallelic crossing over. The cytological investigations of salivary gland chromosomes of the various bar-forms in Drosophila seem to furnish sufficient proof of this.

Stadler's interesting discussion (1954) is concerned also with " repeats", in which "clustered elements" of the same genetic structure can be formed as a complex element of inheritance. By crossing over or translocation position effects may occur. He states, "With regard to the relationships between the gene elements of the complex, the concepts of allelism and locus have little meaning. All members of the complex are homologous with one another : presumably all have arisen through a long series of mutations from some ancestral gene. In a sense, all may be considered allelic to one another." 
Demerec (1955), in his studies on pseudo-allelism, states (p. I6) : "that the regions within the locus where these modifications occur can be recombined by crossing over, showing that they are arranged linearly along the chromosomes", and as early as I933 (see Demerec, I955), he stated that " changes producing different allelomorphs are independent of each other and . . . they might arise by changes in different groups of a gene molecule". As it appears from the present discussion, the concept of interallelic crossing over does not necessarily involve a linear arrangement, although, as mentioned, the presence of the BI-series in Aspergillus indicates that even with interallelic crossing over, molecular exchanges may take place, which, on the basis of genetic analyses, point toward the existence of such.

There is a need for investigations on a series of different organisms in which complex genes occur, and in which it is possible, through the help of gene markers, to determine whether or not the chromatid axis always takes part in the process of crossing over.

\section{SUMMARY}

I. Two different instances of extremely close linkage between the raffinose and the maltose fermenting genes observed in the genus Saccharomyces may be regarded as due to the presence of complex allelic genes.

2. Between these complex genes it is assumed that a process of interallelic crossing over takes place, in which molecular groups are exchanged and which usually results in the formation of two new allelomorphs. Thus from the heterozygote $M_{1}{ }^{{ }{ }^{1}} / m_{1}{ }^{R_{1}}$, two new types, $M_{1}{ }^{R_{1}}$ and $m_{1}{ }^{{ }_{1}}$, may arise through interallelic crossing over. This hypothesis includes the assumption that the enzymes produced through the activity of the genes in question, maltase and $\beta$-h-fructosidase, must be chemically related and that the difference between them can only involve a portion of the whole molecule.

3. The proposed hypothesis involves two types of interallelic crossing over : (I) axial, in which the chromatid axis takes part in the process, and (2) non-axial, in which only a side chain belonging to the complex gene molecule is exchanged with another.

4. Several instances in which mutation has been found to occur in complex genes are discussed.

\section{REFERENCES}

Dzmerec, M. 1955. What is a gene ?-Twenty years later. Amer. Nat., 89, 5-19. DunN, L. C. 1953. The study of complex loci. P. Int. Gen. C. (9), Bellagio, Italy, Pt. I, pp. $156-166$.

DUNN, L. C., AND GLUEGKSOHN-WAELSGH, s. 1953. A genetical study of the mutation "fused" in the house mouse, with evidence concerning its allelism with a similar mutation " kink". F. Genet., 52, 383-39r.

hutchinson, J. B. 1934. The inheritance of leaf shape in Asiatic Gossyprums. I. Genet., 28, 437-513.

Laughinan, J. R. 1949. The action of allelic forms of the gene $A$ in maize. II.

The relation of crossing over to mutation of $A^{b}$. P.N.A.S.. 35, 167-1 78 . 
Laughnan, J. R. 1952. The action of allelic forms of the gene $A$ in maize. IV. On the compound nature of $A^{b}$ and the occurrence and action of its $A^{d}$ derivatives. Genetics, 37, 375-395.

LEWIS, в. B. 1945. The relation of repeats to position effect in Drosophila melanogaster. Genetics, 30, 137-165.

LINDEGREN, c. c. 1949. The yeast cell, its genetics and cytology. St Louis, Educational Publishers, Inc.

MULLER, H. J. 1947. The gene. P.R.S., B, 134, 1-37.

PONTECoRvo, G. 1953. The genetics of Aspergillus nidulans. Advances in Genetics, $5,141-238$.

RHoADES, м. м. I94I. The genetic control of mutability in maize. Cold Spring Harbor Symposia on Quant. Biol., 9, 138-144.

ROPER, J. A. I950. Search for linkage between genes determining a vitamin requirement. Nature, $166,956-957$.

STADLER, L. J. 1954. The gene. Science, $120,811-819$.

THompson, D. H. 1931. The side chain theory of the structure of the gene. Genetics, $x 6,267-290$.

WINGE, $\varnothing$, AND ROBERTS, C. 1952. The relation between the polymeric genes for maltose, raffinose, and sucrose fermentation in yeasts. Compt. Rend. Lab. Carlsberg, Sér. Physiol., 25, 141-171.

WINGE, $\varnothing$., AND ROBERTS, c. 1953. The genes for maltose and raffinose fermentation in Saccharomyces cerevisia, strain Yeast Foam. Ibid., 25, 241-25I.

Winkler, H. 1930. Die Konversion der Gene. Jena, Verlag Gustav Fischer. 